\title{
Regime de proteção de dados pessoais sensíveis e transparência pública: institutos em aparente conflito
}

\author{
Protection system for sensitive personal data and public transparency: \\ institutes in apparent conflict
}

Vilson Pedro Nery

UNAERP -Universidade de Ribeirão Preto

\begin{abstract}
Resumo O objetivo do artigo é analisar em que medida a transparência das ações públicas permite o controle social e o governo aberto, de modo que as informações gerais produzidas pela administração pública fiquem disponibilizadas, inclusive em dados abertos, para consulta pública na Internet, bem como identificar se há algum conflito aparente de normas e se o sistema capitalista usa as amarras burocráticas a seu favor. O método utilizado é o hipotético-dedutivo, com fulcro em pesquisa bibliográfica. Da pesquisa, conclui-se que, na prática, empresas estão utilizando a Lei de Acesso à Informação para implantar modelos de negócios, baseado nas informações produzidas e custeadas pelo Estado. A proteção de dados é outro reforço capitalista, já que a LGPD pode justificar a sonegação de informações essenciais à população, e a perpetuação do sigilo de atividades de instituições bancárias e agências de inteligência.
\end{abstract}

Palavras-chave: Transparência; Proteção de dados; Informações; Sigilo; CapitaLISMO.

\begin{abstract}
ABSTRACr The objective of the article is to analyze the extent to which the transparency of public actions allows social control and open government, so that the general information produced by the public administration is made available, including open data, for public consultation on the Internet, as well as identifying whether there is any apparent conflict of norms and whether the capitalist system uses bureaucratic bonds to its advantage. The method used is the hypothetical-deductive with fulcrum in bibliographic research. The research concludes that, in practice, companies are using the Access to Information Law to implement business models, based on information produced and funded by the State. Data protection is another capitalist reinforcement, since the LGPD can justify the withholding of essential information from the population, and the perpetuation of the secrecy of activities of banking institutions and intelligence agencies.
\end{abstract}

Keywords: Transparency; Data Protection; Information; Secrecy; Capitalism. 


\title{
1. INTRODUÇão
}

Nesse início do século XXI a humanidade assiste aos avanços e aos dois dilemas nunca antes previstos, provocados pela revolução tecnológica como as inovações da informática, nanotecnologia e o tráfego instantâneo de dados, provocando impactos diariamente, revelando novas formas de se fazer as mesmas coisas, aplicadas a todas as áreas de atuação humana. O mundo do trabalho sofreu violenta modificação com a chamada "uberização" 1 das relações de labor, conceito pelo qual o ser humano executa tarefas e negócios mediante à submissão a algoritmos e aplicativos de smartphone e Internet. Na literatura contemporânea, o historiador israelense Yuval Noah Harari (2018) retrata em "21 lições para o século XXI" como a humanidade está sendo influenciada pela Inteligência Artificial (IA). Elementos valorativos como o preço do trabalho, remuneração pelos serviços, avaliação do empenho dos trabalhadores em suas tarefas, tudo é mediado por um algoritmo "arbitrário", um fiscal controlador e intangível que recebe, armazena e trata os dados das pessoas sem que elas consintam previamente.

Para Harari os donos dos dados são donos do futuro:

\begin{abstract}
Nas últimas décadas foi dito às pessoas em todo o mundo que o gênero humano está a caminho da igualdade, e que a globalização e as novas tecnologias nos ajudarão a chegar lá mais cedo. Na verdade, o século XXI poderia criar a sociedade mais desigual da história. Embora a globalização e a internet representem pontes sobre as lacunas que existem entre os países, elas ameaçam aumentar a brecha entre as classes, e, bem quando o gênero humano parece prestes a alcançar a unificação global, a espécie em si mesma pode se dividir em diferentes castas biológicas. (HARARI, 2018, p. 75).
\end{abstract}

$\mathrm{O}$ autor se refere às possibilidades de inovações na área de medicina, com o uso da tecnologia que poderia, inclusive, prever doenças com muita antecedência, mapeando as reações da pessoa ao longo da vida ou mesmo antes dela, ainda na fase embrionária, e descrevendo os impactos e ações que podem levar ao aparecimento de doenças.

A Internet não possui nacionalidade, retrata Marcacini (2016, p. 10):

Como representa um conjunto global de redes de computador interconectadas, não existe nenhum governo, organismo internacional ou entidade que exerça controle ou domínio absoluto sobre a Internet. A regulamentação da rede é efetuada dentro de cada país, que é livre para estabelecer regras de utilização, hipóteses de responsabilidade e requisitos para acesso, atingindo apenas os usuários sujeitos à soberania daquele Estado. Como forma de impedir, investigar e reprimir condutas lesivas na rede, são por vezes necessários esforços conjuntos de mais de um sistema jurídico, dependendo da localização dos infratores e dos serviços por eles utilizados. (MARCACINI, 2016, p. 10).

A Internet foi um instrumento criado para a guerra, portanto em seu início era mais

1 Neologismo inspirado no aplicativo de transporte UBER, o qual significa a designação das novas formas de prestação de serviços em que não há relação entre pessoas, a mediação é feita por aplicativos. 
um artefato a ser utilizado pelas nações beligerantes, como instrumento de opressão e violência, segundo o autor citado:

\begin{abstract}
Criada nos Estados Unidos durante a guerra fria, a Internet nasceu com uma arquitetura descentralizada e em formato de rede. O objetivo disso era assegurar a continuidade de seu funcionamento, ainda que parte do país e de sua infraestrutura simplesmente desaparecesse do mapa como resultado de um ataque nuclear soviético. Assim, não há um centro único de operação ou comando. Todos os pontos podem se conectar com os demais pontos. Enquanto houver dois pontos operantes e um canal de comunicação entre eles, a rede funcionará. Não há uma via única de comunicação, mas uma verdadeira malha de conexões, o que justifica a utilização da palavra "rede" para designá-la. Pode-se comparar essas conexões às muitas ruas de uma cidade, de modo que não há um único caminho a ligar duas residências, situadas em dois endereços quaisquer. Se uma rua estiver em obras - ou, no cenário da guerra fria, for destruída - é possível transitar por outra rua paralela, ou outra, ou ainda outra que dê voltas mais longas mas permita atingir o destino desejado. (MARCACINI, 2016, p. 11).
\end{abstract}

Tardiamente, o legislador brasileiro se debruçou sobre o tema, mas com insuficiente expertise para compreender as complexas e múltiplas relações entre o homem e a máquina, os limites das redes sociais e as possibilidades de interação e invasão de privacidades. Se não há regulação satisfatória, se mesmo a localização e punição de eventual agente que cometa crimes cibernéticos é tarefa hercúlea, é de se imaginar que as dimensões sociais e os novos conflitos estão bem longe de uma solução pacificadora. Da evolução da tecnologia tem-se por efeito as modificações das relações sociais e econômicas entre pessoas naturais e jurídicas, e também o nascimento de novas contendas, para as quais a sociedade precisa propor soluções inovadoras, devendo o Direito também assumir tal atribuição.

O Brasil não é um país isolado do restante do mundo, sofre as influências da geopolítica, da economia em escala global, dos tratados e convenções multilaterais, bem como das novas práticas e modelos de negócios que são gerados por empresas que atuam nesse ambiente em ebulição tecnológica.

Com o propósito de atender aos marcos normativos advindos de acordos multilaterais, visando o combate à corrupção e o enfrentamento dos crimes a ela agregados, o Brasil estabeleceu uma série de inovadores institutos jurídicos e, entre eles, destacamos a Lei de Acesso à Informação, a Lei $n^{\circ} 12.527$, de 2011. Com ela, a publicidade das ações da Administração Pública passou a ser uma regra imposta e o sigilo, uma excepcionalidade. Logo em seguida a ordem jurídica recebeu o Marco Civil da Internet ${ }^{2}$, o que acarretou em uma série de obrigações, definindo conceitos, buscando disciplinar o chamado "ambiente virtual".

Dessa mesma direção veio a Lei Geral de Proteção de Dados, a qual buscou traduzir conceitos jurídicos mais robustamente definidos, no sentido de proteger informações pessoais sensíveis, assim consideradas aquelas que interessam a apenas uma pessoa, não sendo necessário seu reporte ao público. A Lei Geral de Proteção de Dados Pessoais ainda está em fase de implantação no Brasil, mas o processo é lento, o governo não demonstra muito in-

2 LEI No 12.965, de 23 de abril de 2014. Estabelece princípios, garantias, direitos e deveres para o uso da Internet no Brasil. 
teresse em regulamentar a matéria, talvez porque ela seja importante até mesmo para algumas campanhas eleitorais, conforme se verá logo adiante. Posto isso, democratizar as redes sociais e a Internet pode não ser uma opção agradável para algumas agremiações políticas.

Neste artigo trataremos a Lei de Acesso à Informação, e a Lei Geral de Proteção de Dados Pessoais com os acrônimos LAI e LGPD respectivamente, quando não houver prejuízo ao contexto.

\title{
2. AS NORMATIVAS DE DIREITO INTERNACIONAL SOBRE TRANSPARÊNCIA E PROTEÇÃO DE DAdOS PESSOAIS EM FACE dO SISTEMA CAPITALISTA
}

\subsection{Capitalismo}

Esse fenômeno da mundialização das economias privadas não passou despercebido para Coggiola (2019) que retratou, em densa obra, a história do mundo na era do capital, buscando identificar o processo histórico do capitalismo, e percebeu que ele deixa de possuir uma identidade nacional, todavia mantém relação com os países economicamente avançados, em regra sede principal de seus negócios. Empresas e marcas mundiais passaram a enfrentar menores exigências para sua expansão multinacional, com a baixa regulação e taxação atrativa sobre as remessas de lucros, criando o imperialismo capitalista. Algumas imposições de transparência a governos, e proteção de dados produzidos e armazenados em sistemas de informática, são medidas bem mais úteis às empresas do que aos governos e suas populações.

Para esse autor:

\begin{abstract}
O debate sobre o imperialismo capitalista teve como eixos o papel decisivo do monopólio, o surgimento do capital financeiro como produto da fusão do capital bancário e industrial e sua hegemonia sobre as outras formas do capital, o predomínio da exportação do capital sobre a exportação de mercadorias, a divisão do mercado mundial entre os monopólios capitalistas competidores, a conclusão da divisão territorial do mundo. $\mathrm{O}$ embate afunilou na busca de uma interpretação global, que vinculasse e articulasse depressão econômica, expansão colonial, exportação de capital, disputas geopolíticas, nacionalismo xenófobo, racismo e nacionalismo. (COGGIOLA, 2019, p. 631).
\end{abstract}

E o mundo começou a conhecer a desenfreada expansão das relações negociais capitalistas e suas dimensões de acumulação, mitigação de fronteiras e, como não poderia deixar de ser, o desenvolvimento de práticas antiéticas e criminosas. Foi por essa razão que os diversos países ocidentais se reuniram para debater e instituir normas legais e de controle para afastar as práticas de corrupção e lavagem de dinheiro, ações tão comuns nas relações capitalistas.

De acordo com as palavras de Chauí (2000) o filósofo Locke descreve Deus como sendo o grande artífice, engenheiro, que fez uma obra, o mundo em que vivemos, e a Ele pertence. Aí criou o homem à sua imagem e semelhança, transferindo-lhe o domínio e a propriedade de sua obra. Deu o mundo ao homem, para que nele reinasse e, ao expulsá-lo do Paraíso, não lhe retirou o domínio do mundo, mas alertou o homem que doravante obteria as coisas com o suor de seu rosto. Portanto, para Locke, a origem da propriedade (bens) é o trabalho, e o direito à propriedade privada seria fruto legítimo do trabalho. 
Completa a autora:

De fato, embora o capitalismo estivesse em vias de consolidação e o poderio econômico da burguesia fosse inconteste, o regime político permanecia monárquico e poderio político e o prestígio social da nobreza também permaneciam. Para enfrentá-los em igualdade de condições, a burguesia precisava de uma teoria que lhe desse legitimidade tão grande ou maior do que o sangue e a hereditariedade davam à realeza e à nobreza. Essa teoria será a da propriedade privada como direito natural e sua primeira formulação coerente será feita pelo filósofo inglês Locke, no final do século XVII e início do século XVIII (CHAUÍ, 2000, p. 519).

Nessa quadra da história resta muito clara a relação intrincada entre o capitalismo e a propriedade privada, sendo que essa última seria reconhecida como um direito de natureza fundamental pela Constituição Federal do Brasil.

\subsection{Neoliberalismo}

Estudioso talhado na disciplina de Economia, Ciência que lecionou por décadas, o professor Ávila (2017) apresenta uma definição lapidada para a cognoscência do fenômeno do neoliberalismo, buscando fazer um recorte histórico do nascimento do estado e da sociedade liberal após as revoluções. Segundo o autor, o neoliberalismo é mais prático do que teórico e possui a pretensa aptidão para beneficiar os mais endinheirados. Em relação ao liberalismo, para esse autor:

[...] foi a doutrina que embasou ideologicamente as revoluções antiabsolutistas que ocorreram na Europa (Inglaterra e França) ao longo dos séculos XII e XVIII e a luta pela independência dos Estados Unidos. Na base inicial do liberalismo prevaleceram as palavras de ordem: laisser-faire [sic] ("Deixai fazer, deixar passar") proclamando a mais absoluta liberdade de produção e comercialização de mercadorias. (ÁVILA, 2017, p. 58).

Portanto, o neoliberalismo pode ser descrito como sendo um fenômeno lastreado nas premissas de prevalência dos interesses do capital sobre aqueles representados pelo trabalho; que o poder dos sindicatos de trabalhadores deve ser aniquilado; e que os obstáculos para a acumulação capitalista devem ser afastados, inclusive no plano interno das nações, já que - e isso é o que interessa ao nosso estudo, guardando escopo com nosso propósito - o capital não possui pátria e nem fronteiras, devendo os estados permitirem a sua livre circulação.

$\mathrm{Na}$ medida em que os países diminuem suas regras de controle, por reclamação do neoliberalismo, e afastam as amarras para a livre circulação de produtos, riquezas, negócios e contratos, os novos modais tecnológicos vêm bem a calhar. Com a livre circulação de dinheiro por meio digital, graças às novas possibilidades das tecnologias, os negócios e contratos passam também a representar uma ameaça contra a intimidade das pessoas naturais. Os aplicativos de redes sociais, mesmo aqueles intitulados enganosamente como "gratuitos", capturam, cadastram e selecionam dados pessoais de seus usuários, obtendo monetização. O lucro é obtido pela circulação de informações naturais no ambiente digital 
e de Internet, as quais são capturadas à revelia dos interessados e dos controles estatais, sendo um negócio absolutamente à margem da ética e dos controles.

Reportagem não tão recente publicada em 27/07/2017 pela jornalista Rosa Jimenez Cano na plataforma digital do jornal El País ${ }^{3}$, mostra que as novas gerações de aparelhos eletrodomésticos, como os "robôs" de limpeza, possuem programação para detectar espaços vazios nas casas dos consumidores e mesmo identificar as preferências de seus usuários, reportando tudo para uma empresa que fará ofertas de produtos "na medida" das necessidades e de acordo com o estado emocional do consumidor, apostando em suas fraquezas.

\subsection{Convenção de Mérida}

No ano de 2003 o Brasil participou da Convenção das Nações Unidas Contra a Corrupção e, rapidamente, o estado brasileiro internalizou a norma no sistema jurídico por meio do Decreto $n^{0} 5.687$, de 31 de janeiro de 2006, evidenciando a grande preocupação com o tema da corrupção.

Nesse texto normativo, a palavra transparência foi escrita 09 (nove) vezes, e sua abundância no contexto da Convenção bem demonstram a importância que doravante deveria ser devotada às questões relacionadas à disponibilização pública de documentos e atos da Administração estatal.

Destacamos do texto:

[...] 1. Cada Estado Parte, de conformidade com os princípios fundamentais de seu ordenamento jurídico, formulará e aplicará ou manterá em vigor políticas coordenadas e eficazes contra a corrupção que promovam a participação da sociedade e reflitam os princípios do Estado de Direito, a devida gestão dos assuntos e bens públicos, a integridade, a transparência e a obrigação de render contas. [...]

3. Cada Estado Parte considerará a possibilidade de adotar medidas legislativas e administrativas apropriadas, em consonância com os objetivos da presente Convenção e de conformidade com os princípios fundamentais de sua legislação interna, para aumentar a transparência relativa ao financiamento de candidaturas a cargos públicos eletivos e, quando proceder, relativa ao financiamento de partidos políticos.

4. Cada Estado Parte, em conformidade com os princípios de sua legislação interna, procurará adotar sistemas destinados a promover a transparência e a prevenir conflitos de interesses, ou a manter e fortalecer tais sistemas.

No sentido de dar efetividade aos itens 3 e 4 da Convenção das Nações Unidas Contra a Corrupção o Estado brasileiro editou a Lei $n^{0} 12.527$, de 2011, conhecida como a Lei de Acesso à Informação (LAI). Por meio dela, criaram-se vínculos de ação aos agentes públicos que devem disponibilizar publicamente, principalmente na Internet, informações sobre as diversas dimensões das políticas públicas.

Tratada como transparência ativa, foi instituída a obrigação de publicação e

3 "Roomba, o aspirador de pó espião - Fabricante do robô de limpeza admite que pretende vender dados sobre as plantas das residências" Disponível em: <https://brasil.elpais.com/brasil/2017/07/26/tecnologia/1501047333_849632.html>. Acesso em: 25 nov. 2020. 
disponibilização das informações relacionadas às receitas ingressantes nos cofres do fisco, despesas com custeio da estrutura administrativa e pagamentos de pessoal, contratos, discussão sobre orçamento e audiências públicas, entre outras de igual relevância. De acordo com a LAI, tais informações e documentos devem ser disponibilizados nos portais institucionais dos órgãos e entidades públicos.

Com essa medida é possível verificar, por exemplo, se determinada pessoa ou empresa doou recursos para uma campanha eleitoral e se após a eleição do seu "protegido" passou a celebrar negócios com as entidades da administração pública, sob o novo gestor eleito. Na atualidade, todos os contratos celebrados pelos governos, inclusive as comprovações da realização de obras ou prestação de serviços, devem ser publicados nos portais de transparência, inclusive com a relação dos empenhos e pagamentos efetuados.

Naquelas situações em que a informação almejada não esteja disponível para consulta pública, independente da causa, foi criada a dimensão da transparência passiva, em que o ente público é provocado e deve franquear o acesso à informação especificamente buscada, salvo nas raras hipóteses de sigilo que reclama uma prévia classificação de acordo com critérios da LAI.

A Lei de Acesso à Informação (LAI) foi considerada um marco na publicidade que deve ser emprestada aos negócios públicos e saudada como sendo mais um valoroso instrumento que permite à população a concretude do controle social da atuação dos agentes públicos.

Para Martins Junior:

A publicidade é um dos expoentes mais qualificados da transparência, obrigando a Administração Pública à exposição de todo e qualquer comportamento administrativo e conferindo certeza a condutas estatais e segurança aos administrados - resultante que é do princípio democrático impositivo da diafanidade [sic]. A publicidade é o primeiro estágio da transparência administrativa, ao permitir o conhecimento e o acesso; porém, avança sobre os tributos dados por aquela, viabilizando outras funções, mais complexas e, igualmente derivadas desta. Por esta razão, abdica-se de uma concepção restritiva, apesar da notável evolução da publicidade, de um dever administrativo ao reconhecimento do direito subjetivo público de acessibilidade aos assuntos administrativos (MARTINS JUNIOR, 2010, p. 37).

É possível deduzir que os interesses capitalistas foram considerados no processo de produção das normas que tratam da transparência nas ações e atos da administração pública. Afinal, muitas informações armazenadas pelas entidades públicas são disponibilizadas graciosamente, e é possível minerar dados de grande utilidade para a prospecção de negócios.

\subsection{Convenção Americana de Direitos Humanos}

Diferente da Convenção Contra a Corrupção, foram necessários 22 anos para que a Convenção Americana sobre Direitos Humanos (Pacto de São José da Costa Rica), aprovada em 22 de novembro de 1969, fosse reconhecida internamente e assinada pelo Brasil, conforme o Decreto $n^{\circ} 678$, de 06 de novembro de 1992. Antes disso o tema dos direitos humanos já era motivo de preocupação da Organização das Nações Unidas (ONU). Os horrores da Segunda Guerra Mundial, principalmente as atrocidades do nazismo impactaram o mundo 
de tal modo que em 1948 foi estabelecida pela Organização das Nações Unidas a Declaração Universal dos Direitos Humanos, como norte para um mundo sob novas bases ideológicas. O Brasil foi um dos 58 estados-membro a subscrever o documento multilateral.

Comparando o alcance do texto de ambos os documentos, a Convenção Americana sobre Direitos Humanos evidencia que buscou detalhar com maior profundidade a proteção que deve ser tributada à pessoa humana no âmbito das relações com as instituições estatais e, considerando a Ditadura Militar em vigor no Brasil por longo período, é possível deduzir que seja esse o motivo para a demora de duas décadas na aceitação do texto convencional referente a um tema tão relevante.

Da Convenção Americana sobre Direitos Humanos, destacamos:

\begin{abstract}
ARTIGO 11
Proteção da Honra e da Dignidade

1. Toda pessoa tem direito ao respeito de sua honra e ao reconhecimento de sua dignidade.2. Ninguém pode ser objeto de ingerências arbitrárias ou abusivas em sua vida privada, na de sua família, em seu domicílio ou em sua correspondência, nem de ofensas ilegais à sua honra ou reputação.3. Toda pessoa tem direito à proteção da lei contra tais ingerências ou tais ofensas (BRASIL, PGESP, 1992).
\end{abstract}

Denota-se que uma das garantias que o texto convencional busca resguardar é justamente a vida privada da pessoa humana, assim considerados os seus atributos pessoais, os quais não podem ser expostos à curiosidade pública, porque somente à pessoa natural interessa. A vida privada e a intimidade são dimensões do mesmo direito de permitir que a pessoa humana mantenha sigilo sobre seus hábitos, sua religião, opinião política e sindical, sexualidade, não existindo interesse público em sua divulgação.

Sobre a vida privada, conforme elaboração de Loureiro (2020):

\begin{abstract}
A noção de privacidade abrange três esferas distintas do indivíduo: a esfera íntima ou do segredo, que engloba os aspectos pessoais que devem ser subtraídos do conhecimento de terceiros; a esfera privada, da qual faz parte o resto das informações que uma pessoa não partilha, ou não deseja partilhar, com estranhos, mas apenas com um grupo restrito e definido de terceiros e; a esfera pública, que compreende todos os dados ou informações sobre a pessoa que são conhecidos do público e das quais o público pode livremente tomar conhecimento. (LOUREIRO, 2020, p. 544).
\end{abstract}

\title{
3. AS NORMATIVAS DE DIREITO INTERNO SOBRE TRANSPARÊNCIA E PRO- TEÇÃO DE DADOS PESSOAIS EM FACE DO SISTEMA CAPITALISTA
}

\subsection{Lei de Acesso à Informação - LAI}

Conforme alinhavado anteriormente, buscando emprestar efetividade à transparência da Administração Pública, o legislador decidiu pela criação da Lei de Acesso à Informação. A LAI aborda alguns conceitos jurídicos em seu artigo $4^{\circ}$ : 
I - informação: dados, processados ou não, que podem ser utilizados para produção e transmissão de conhecimento, contidos em qualquer meio, suporte ou formato;

II - documento: unidade de registro de informações, qualquer que seja o suporte ou formato;

III - informação sigilosa: aquela submetida temporariamente à restrição de acesso público em razão de sua imprescindibilidade para a segurança da sociedade e do Estado;

IV - informação pessoal: aquela relacionada à pessoa natural identificada ou identificável;

V - tratamento da informação: conjunto de ações referentes à produção, recepção, classificação, utilização, acesso, reprodução, transporte, transmissão, distribuição, arquivamento, armazenamento, eliminação, avaliação, destinação ou controle da informação;

VI - disponibilidade: qualidade da informação que pode ser conhecida e utilizada por indivíduos, equipamentos ou sistemas autorizados;

VII - autenticidade: qualidade da informação que tenha sido produzida, expedida, recebida ou modificada por determinado indivíduo, equipamento ou sistema;

VIII - integridade: qualidade da informação não modificada, inclusive quanto à origem, trânsito e destino;

IX - primariedade: qualidade da informação coletada na fonte, com o máximo de detalhamento possível, sem modificações (BRASIL, 2011).

O maior objetivo da Lei de Acesso à Informação foi demonstrado com a imposição de divulgação pública de todos os documentos e informações, de acordo com a redação do artigo $5^{\circ}$ :

Art. $5^{\circ}$ É dever do Estado garantir o direito de acesso à informação, que será franqueada, mediante procedimentos objetivos e ágeis, de forma transparente, clara e em linguagem de fácil compreensão (BRASIL, 2011).

Isso quer dizer que a Administração deve disponibilizar publicamente, via portais institucionais na Internet, todas as informações e documentos produzidos, permitindo as consultas públicas, inclusive facilitando seu download. Quando tal informação ou documento for de grande monta e não comportar a divulgação por essas mídias, o interessado será orientado sobre o endereço físico onde pode consultar o objeto de interesse e inclusive fotocopiar a informação almejada.

A norma é aberta, seus conceitos são amplos e o intérprete necessita atentar-se aos cuidados necessários para que as entidades públicas não sejam apenas uma grande "big data" destinada à sustentar a prospecção de negócios e relegando o interesse primário - a prestação de serviços à população - a um plano de inferioridade.

\subsection{Lei Geral de Proteção de Dados Pessoais - LGPD}

Ocorre que a socialização da informação e a divulgação de documentos, atos, contratos, dados telemáticos em poder da Administração podem comprometer a intimidade das pessoas. É fácil compreender que o grande controlador de bancos de dados sobre pessoas e 
empresas não são os particulares, mas sim o Estado. Desde o nascimento, a criança recebe os atendimentos médicos em hospitais públicos, os nascimentos são registrados em serventias de registro civil de pessoas naturais, com informações que só interessam à família do recém-nascido.

Já na idade escolar as pessoas são matriculadas em escolas na busca por letramento, e ali deixam registradas informações sobre toda a vida discente, as preferências alimentares e inclusive eventuais alergias ou propensão a determinadas patologias. Passando para a vida adulta, quando deseja se casar, a pessoa deve se habilitar perante o registrador público e a ele franquear todas as suas informações, as quais ficam registradas naquela serventia, algumas acessíveis ao público em geral. Para simplificar, vamos citar os bancos de dados mantidos pelas autarquias de trânsito, as quais retratam o comportamento da pessoa enquanto dirige e trafega pelas vias públicas. Há o setor de registro geral que emite os documentos de identificação pessoal; os órgãos tributários que guardam a vida do contribuinte; e a justiça eleitoral, habilitada a recolher informações biométricas, endereços e outras informações pessoais dos eleitores.

Falta ainda mencionar as pessoas jurídicas em geral, cujos registros cabem ao RCPJ (registro civil da pessoa jurídica) ou autarquia vinculada ao registro de empresas, geralmente à Junta Comercial dos estados da federação. Além dos dados relacionados às pessoas jurídicas, são coletadas e armazenadas informações sobre as pessoas físicas que integram essas entidades coletivas (sócios).

E como fazer para proteger os dados pessoais sensíveis que constam desses repositórios? E afinal, o que são dados pessoais sensíveis?

Buscamos a explicação da LGPD:

\footnotetext{
Art. $5^{\circ}$ Para os fins desta Lei, considera-se:

I - dado pessoal: informação relacionada à pessoa natural identificada ou identificável;

II - dado pessoal sensível: dado pessoal sobre origem racial ou étnica, convicção religiosa, opinião política, filiação a sindicato ou a organização de caráter religioso, filosófico ou político, dado referente à saúde ou à vida sexual, dado genético ou biométrico, quando vinculado a uma pessoa natural;

III - dado anonimizado: dado relativo ao titular que não possa ser identificado, considerando a utilização de meios técnicos razoáveis e disponíveis na ocasião de seu tratamento;

IV - banco de dados: conjunto estruturado de dados pessoais, estabelecido em um ou em vários locais, em suporte eletrônico ou físico;

V - titular: pessoa natural a quem se referem os dados pessoais que são objeto de tratamento; (BRASIL, 2018).
}

Nesse cenário de ebulição tecnológica e tráfego facilitado de informações pela Internet e por aplicativos, a LGPD impõe uma série de restrições, inclusive prevendo sanções pela desobediência. Posto isso, são conjugados os interesses da pessoa com o viés da proteção dos direitos humanos, conforme os fundamentos de tratamento de dados: 
Art. $2^{\circ} \mathrm{A}$ disciplina da proteção de dados pessoais tem como fundamentos:

$\mathrm{I}$ - $\mathrm{o}$ respeito à privacidade;

II - a autodeterminação informativa;

III - a liberdade de expressão, de informação, de comunicação e de opinião;

IV - a inviolabilidade da intimidade, da honra e da imagem;

V - o desenvolvimento econômico e tecnológico e a inovação;

VI - a livre iniciativa, a livre concorrência e a defesa do consumidor; e

VII - os direitos humanos, o livre desenvolvimento da personalidade, a dignidade e o exercício da cidadania pelas pessoas naturais. (BRASIL, 2018).

Proteger dados pessoais não significa que eles estão inacessíveis, mas que haja todo um cuidado com seu tratamento que deve ser feito por agentes habilitados.

Na obra coletiva Lei Geral de Proteção de Dados Pessoais Manual de Implementação, Josmar Lenine Giovannini Junior esclarece que:

Os operadores deverão ser devidamente treinados e alertados das suas responsabilidades referentes a tais tratamentos. É importante que eles possuam contratos de confidencialidade específicos com as empresas nas quais trabalham, reforçando as suas responsabilidades em tais tratamentos, além de terem conhecimento sobre as sanções cabíveis às empresas nos casos de incidentes de violação de segurança, bem como de possíveis responsabilizações legais pessoais que poderão receber, advindas de episódios de violação de segurança de dados que estejam sob suas responsabilidades. Uma das causas geradoras de episódios de violação de segurança é a imperícia no tratamento com os dados pessoais. (GIOVANNINI JUNIOR, 2019, p. 173).

O regime de proteção de dados passou a merecer atenção quando o Brasil resolveu adotar medidas para regular o uso da Internet, na medida em que o ambiente virtual passou a ser uma espécie de espaço perigoso, que facilitava o cometimento de crimes e a anonimização da autoria. A primeira grande medida foi o mapeamento da Internet, com a participação dos diversos interessados, e a pactuação do Marco Civil, buscando respeito ao ambiente civilizatório.

\subsection{Marco Civil da Internet}

Para Marcacini (2016) a discussão e aprovação do Projeto de Lei nº 2.126, de 2011 na Câmara dos Deputados, com passagem meteórica pelo Senado Federal, mostra a brevidade pelo qual o assunto merecia regulação. A Lei n 12.965 , de 23 de abril de 2014, "estabelece princípios, garantias, direitos e deveres para o uso da Internet no Brasil”, conforme consta em sua ementa.

Em pouco mais de 30 artigos, a Lei no 12.965 trata de garantir a proteção dos direitos humanos, pluralidade, livre iniciativa e finalidade social da rede. Também revela a intenção da democratização do acesso à Internet, da inovação tecnológica e a adesão aos padrões adequados.

No sentido de oferecer eficácia à proteção da intimidade dos usuários, os artigos 10 , 11 e 12 tratam da "Proteção aos Registros, aos Dados Pessoais e às Comunicações Priva- 
das", restando evidente que a informação, para ser publicada, deve conter interesse público, mas aquelas que interessam somente à pessoa natural, inclusive suas comunicações, merecem proteção.

A privacidade foi mencionada por Marcacini quando afirma que:

Um dos temas jurídico-políticos mais candentes em nossa atual sociedade da informação refere-se à defesa da privacidade individual e sua precisa delimitação. As modernas tecnologias da informação e comunicação, especialmente a capacidade que têm os computadores de armazenar e processar informações em escala e velocidade crescentes, têm proporcionado poderosas ferramentas que tanto trazem muitos benefícios à sociedade, como podem ser usadas para atentar contra a privacidade. Governos e corporações têm em suas mãos amplos meios técnicos de formar bases de dados populacionais, em que se anote cada detalhe da vida privada dos indivíduos, e ainda classificar e localizar rapidamente as fichas eletrônicas segundo múltiplos critérios de escolha, conforme desejado pelo operador de tais cadastros. Na verdade, em razão da exponencial evolução dos computadores, uma máquina padrão que hoje é vendida ao público em um supermercado qualquer tem mais poder de processamento e armazenamento de dados do que os caros supercomputadores de apenas duas décadas atrás, que somente pouquíssimas entidades públicas ou privadas tinham condições de adquirir. Um computador que hoje pode estar instalado no quarto de crianças, tem processamento e armazenamento bastantes para criar, manter e tratar cadastros populacionais de países inteiros. De outro lado, o avanço tecnológico também proporcionou meios de proteção à privacidade, especialmente mediante o uso da criptografia moderna, capazes de ao menos neutralizar ou minimizar os riscos advindos da própria tecnologia (MARCACINI, 2016, np)

Desse modo, a Administração pública detém o maior banco de cidades referentes às pessoas naturais, com as informações consideradas sensíveis pela norma, e sempre que necessitar cumprir as obrigações de transparência, precisa se sujeitar às técnicas de anonimização e pseudonimização que trata a LGPD.

\subsection{Conceitos aplicados à espécie}

Para facilitar o entendimento sobre alguns dos conceitos tratados na Lei de Acesso à Informação e na Lei Geral de Proteção de Dados Pessoais, vamos buscar descrever sua aplicabilidade:

Transparência ativa: ocorre quando a entidade pública ou órgão da administração divulga em portais da Internet, e em outros meios, as informações sobre as políticas públicas e as diversas rotinas que interessam à população.

Transparência passiva: é a busca junto à administração pelos meios eletrônicos (ouvidorias, portais de transparência, etc.) de uma informação que não foi disponibilizada. Geralmente é formalizado um pedido de informação com fundamento na LAI.

Anonimização: quando um documento público contém uma informação de pessoa natural identificada ou identificável, e não há interesse público na divulgação, ocorre o tratamento de anonimização, mediante processo manual (riscar) ou eletrônico (aplicação de tarjas, por exemplo). 
Pseudonimização: quando um documento contém informação que pode identificar a pessoa, o nome dela pode ser pseudonimizado, ou receber um apelido que proteja sua identidade.

Dado pessoal: é aquela informação relacionada à pessoa natural identificada ou identificável, cuja publicidade não é de interesse público, embora seja possível seu tratamento quando for de interesse da Administração.

Dado pessoal sensível: é um dado pessoal sobre a origem racial ou étnica, convicção religiosa, opinião política, filiação a sindicato ou a organização de caráter religioso, filosófico ou político, dado referente à saúde ou à vida sexual, dado genético ou biométrico, quando vinculado a uma pessoa natural. O tratamento desses dados é possível, mas o "vazamento" é sancionável.

Banco de dados: é o conjunto estruturado de dados pessoais, estabelecido em um ou em vários locais, em suporte eletrônico ou físico.

Tratamento da informação: é toda operação realizada com dados pessoais como coleta, produção, recepção, classificação, utilização, acesso, reprodução, transmissão, distribuição, processamento, arquivamento, armazenamento, eliminação, avaliação ou controle da informação, modificação, comunicação, transferência, difusão ou extração.

Consentimento ou assentimento: é a manifestação livre, informada e inequívoca pela qual a pessoa natural concorda com o tratamento de seus dados pessoais para uma finalidade determinada.

\section{Possível Conflito aparente de normas destinadas a regular o MESMO OBJETO}

As imposições da transparência para os documentos e as decisões produzidas pelos agentes de estado e a necessidade de proteção de dados pessoais sensíveis são, portanto, imposições às quais o Brasil se submeteu no momento em que concordou com as nações civilizadas e anuiu com a subscrição de acordos e tratados internacionais. Ao escopo de nosso artigo interessam os tratados que propõem a transparência pública como inibidor da corrupção, e a proteção de dados pessoais como uma das dimensões de proteção da intimidade da pessoa humana.

Sempre é bom alertar que os chamados países desenvolvidos pregam a adoção de algumas medidas que podem ser atraentes às nações emergentes, mas são ainda mais relevantes ao ambiente capitalista e aos interesses das nações economicamente fortes e empresas transnacionais.

Como observa Arruda (2012):

O caráter parasitário da oligarquia financeira fica patente quando se observa os superlucros obtidos através dos empréstimos. Durante a Primeira República, foram ao todo 27 empréstimos, que contribuíram para deixar as veias do Brasil cada vez mais abertas, assim como os trabalhadores do campo e da cidade cada vez mais miseráveis. Como resultado da subserviência das classes dominantes brasileiras (que jogavam o ônus de sua opção política nos ombros das classes subalternas), dos juros extorsivos, das cláusulas leoninas e das polpudas comissões, chega-se à constatação que o Brasil exportou mais capital do que importou. (ARRUDA, 2012, p. 138). 
Desse modo, é sempre saudável lembrar que as grandes potências não possuem tradição de punir os seus agentes envolvidos em corrupção, a não ser naquelas situações em que a opinião pública toma conhecimento dos grandes escândalos, como o banco Lehman Brothers Holdings Inc., de Nova Iorque, que foi alçado ao "olho do furacão" em 2008, após a crise do subprime ${ }^{4}$. Ou a falência da Enron Corporation, empresa de ramo de energia sediada no estado do Texas (EUA), que chegou a possuir a força de 21 mil funcionários em seu auge, mas quebrou deixando um rastro de prejuízos aos investidores, empregados e suas famílias. Basta dizer que é bastante raro que instituições financeiras sejam sancionadas por sua colaboração com a lavagem de dinheiro obtido por meio de corrupção, tráfico de drogas ou semelhantes esquemas criminosos. Também é necessário reconhecer que o pioneirismo em violação de dados pessoais, incluindo a quebra e acesso indevido a dados telemáticos e telefônicos, cabe aos Estados Unidos, vide escândalo denunciado por Edward Snowden ${ }^{5}$, WikiLeaks ${ }^{6}$ e Cambridge Analytica ${ }^{7}$.

Nos três casos não há notícia de sanção imposta aos agentes públicos e às empresas privadas que se beneficiaram e enriqueceram com o uso de dados pessoais de terceiros, sem o consentimento delas, e utilizando métodos tidos como antiéticos. Igualmente as nações tidas como desenvolvidas não foram capazes de propor regras que vedassem a captura e o uso de dados que permitem o mapeamento de emoções das pessoas, como ocorre o tempo todo pelo uso de aplicativos, colocando a Inteligência Artificial a serviço do lucro e da violação da vontade das pessoas.

Isso impactou na democracia planetária, segundo Loureiro:

\begin{abstract}
Eventos recentes como as eleições presidenciais de vários países e o processo de saída da Inglaterra da União Europeia (Brexit) reforçaram a tese da mercantilização dos dados pessoais e de seu alto valor de mercado diante das informações e conhecimentos estratégicos. Tanto é assim que empresas da web são usadas apenas para coleta e "venda" de dados pessoais e perfis da personalidade, e mesmo pequenos fornecedores de produtos e serviços coletam e tratam dados pessoais de seus clientes, como nome, telefone, endereço, e-mail, CPC, data de aniversário etc., ainda que isso seja completamente desnecessário para a realização de sua atividade. (LOUREIRO, 2020, p. 541).
\end{abstract}

4 O escândalo do subprime foi uma crise financeira que ocorreu em 24 de julho de 2007, com a queda do índice Dow Jones motivada pela concessão de empréstimos hipotecários de alto risco, prática que arrastou vários bancos a situação de insolvência, repercutindo sobre as bolsas de valores de diversos países.

5 Analista de sistemas da agência NSA, dos Estados Unidos. Denunciou a existência de vários programas de vigilância global que invadiam comunicações pessoais. A revelação foi feita por meio de reportagens dos jornais The Guardian e The Washington Post, detalhando o funcionamento do programa PRISM do governo dos EUA.

6 No ano de 2010 a página WikiLeaks publicou documentos confidenciais do governo dos Estados Unidos, com grande repercussão mundial graças às revelações de violações de privacidade. A página, administrada por The Sunshine Press, foi lançada em dezembro de 2006 e no ano seguinte já possuía 1,2 milhão de documentos. Seu principal editor e porta-voz é o jornalista Julian Assange, atualmente preso por causa dessas publicações.

7 Cambridge Analytica é uma empresa de tecnologia que combina mineração e análise de dados com comunicação estratégica para o processo eleitoral. No ano de 2014 participou de 44 campanhas políticas. Em 2015 tornou-se conhecida como a empresa de análise de dados e inteligência estratégica que trabalhou para a campanha presidencial de Donald Trump e também para fomentar a saída do Reino Unido da União Europeia, via popularização do Brexit. É alvo de investigação criminal nos EUA e Reino Unido. 
A despeito das controvérsias, é dever da Administração pública cumprir as determinações da Lei de Acesso à Informação e disponibilizar todos aqueles dados e documentos indicados nos artigos $7^{\circ}$ e $8^{\circ}$, podendo utilizar a Internet e as redes sociais, além dos portais institucionais. Quando a informação não puder ser disponibilizada pelos meios digitais, o interessado pode pedir pessoalmente ou por meio dos canais oficiais como as ouvidorias, e o prazo de resposta também é definido na lei: 20 dias, com uma prorrogação de outros 10, se justificado.

Mas quando o documento, arquivo digital ou impresso, conter informações pessoais sensíveis como aquelas mencionadas no art. $5^{\circ}$ da Lei Geral de Proteção de Dados Pessoais, não poderá ser entregue a terceiros, mesmo que haja solicitação com fundamento na Lei de Acesso à Informação. O tratamento desses dados só pode ocorrer quando o "dono" dos dados emprestar seu assentimento, ou quando for hipótese de existência de interesse público na medida, conforme previsto no artigo $7^{\circ}$ da norma em referência, mas tal necessidade de tratamento reclama fundamentação.

Algumas empresas, conhecidas popularmente como startups, utilizam os mecanismos da LAI com muita competência para alavancarem seus negócios privados e prospectarem clientes, e fazem isso a partir das informações contidas nos bancos de dados da administração pública. Basta solicitar uma lista de fornecedores de medicamentos, por exemplo, que, a rigor, são publicadas em balanços ou prestações de contas entregues aos órgãos de controle, mas em arquivos com formatos que impedem o tratamento. Desse modo, a LAI permite o acesso em documentos formatados em dados abertos, nos quais é muito comum a existência de informações sensíveis.

Utilizando o exemplo dos fornecedores de medicamentos, é possível que a aquisição possua relação com um paciente identificável, o qual solicitou via judicial a obtenção de determinado medicamento, de modo que no processo administrativo de compra imposto judicialmente, possivelmente à margem do processo licitatório ordinário, estejam contidas informações sensíveis.

Ademais, as empresas concorrentes podem utilizar esse tipo de informação para beneficiar o seu modelo de negócios e, eventualmente, ter acesso às patentes e aos registros que pertenceriam a outras pessoas jurídicas. $\mathrm{O}$ acesso à lista de pessoas sancionadas com multas impostas pelo poder de polícia, ou contribuintes que foram convocados pelo Fisco para justificarem determinados rendimentos, são outros exemplos de como a proteção de dados pessoais e as normas de transparência reclamam tratamento com máxima cautela.

\section{Conclusão}

Em nossa breve incursão sobre o tema da transparência das informações públicas em contraposição à proteção de dados pessoais sensíveis, nos foram permitidas duas conclusões sobre o tema. A primeira delas se relaciona diretamente com o objetivo inicialmente pensado, o qual foi buscar a existência de um conflito aparente de normas, um choque entre a proteção de dados pessoais sensíveis com a obrigação de transparência. O propósito inicial foi identificar eventuais pontos de conflitos entre a aplicação da Lei de Acesso à Informação, destinada à publicidade e transparência dos atos e documentos públicos, com o dever de proteção de dados pessoais contido na Lei Geral de Proteção de Dados Pessoais. 
No curso de nossas buscas identificamos outras dimensões que igualmente mereceram relevância neste artigo e a elas foi dada a atenção merecida como, por exemplo, a constante evolução tecnológica e as ameaças reais à democracia vivida por algumas nações nesse Século XXI. De fato, é saudável que os gestores públicos e as entidades da administração dialoguem com a sociedade, publicando em tempo real os documentos que registram suas ações. Quando esse acervo, independentemente de seu formato, físico ou digital, conter informações que interessam somente à esfera privada de um indivíduo, identificado ou identificável, deve obrigatoriamente ser aplicado o filtro da LGPD no tratamento da informação.

Ao efetuar o tratamento de informações e documentos públicos, o agente deve fazer constantemente a pergunta sobre a existência do interesse público naquelas situações concretas, e a resposta positiva somente poderá ser obtida se for feita a composição entre as duas normas, de transparência pública e de proteção de dados privados. Porém, se houver risco ao indivíduo em sua singularidade, quando as informações conterem elementos sobre a sua esfera privada, a divulgação reclama o assentimento do titular desses dados e informações. Preferencialmente, o tratamento de informações sensíveis deve ocorrer em ambiente seguro e controlado, e somente pelo tempo que for necessário.

Identificamos uma segunda dimensão sobre o tema, em vertente que ameaça a individualidade e a democracia contemporânea, em igual intensidade. A doutrina nacional retrata que o Brasil sofre o fenômeno da modernidade tardia, nossa classe dominante se esforça para atender aos interesses do capitalismo global e, nesse processo, consegue até mesmo conter a utopia do estado do bem-estar social. A aderência imediata às normas de transparência das ações do Estado e de seus agentes se amolda aos interesses do grande capitalismo, o qual faz do acesso aos bancos de dados estatais uma fonte para modelos de negócios. A LAI foi criada com o propósito de facilitar o controle social, mas na prática se transforma em mais um instrumento de feições capitalistas. A proteção de dados ressaltada pela LGPD também é outra proposta que apresenta narrativa de defesa da cidadania, com a restrição necessária à defesa e preservação da intimidade de pessoas naturais, mas na prática permite que uma série de abusos cometidos por empresas multinacionais sigam em curso. Basta dizer que a mineração de dados em redes sociais e publicações na Internet são largamente utilizadas para a "fidelização" de clientela, sem que essas pessoas deem seu consentimento, e é muito comum que a pessoa dê um "like" em um produto visto na Internet e, logo em seguida, sofra um assédio digital por meio de propaganda de bens e serviços que não solicitou e nem assentiu com esse tipo de abordagem.

Ao concluir o artigo podemos deduzir que a Lei Geral de Proteção de Dados é inoperante com relação aos diversos abusos de elevada grandeza como o uso de informações pessoais garimpadas por aplicativos em redes sociais e prática lucrativa para algumas corporações conhecida como monetização, mesmo que o titular dos dados não tenha assentido ou sequer tenha conhecimento de que suas informações são objeto de negócio. A LGPD não apresentou satisfatoriamente nenhuma proposta de sanção aos desvios de finalidade no tratamento das informações obtidas por aplicativos e redes sociais, e a inexistência (até esta data) de uma Autoridade Nacional de Proteção de Dados (ANPD) legalmente designada, e do Conselho Nacional de Proteção de Dados Pessoais e da Privacidade, contribui com o ambiente de insegurança jurídica. 
A Lei de Acesso à Informação acabou sendo um elemento facilitador do capitalismo para que empresas acessem documentos e pesquisas produzidas pelo Estado na condução dos propósitos públicos. Vedar a divulgação de informações sensíveis como propõe a LGPD é uma medida importante, mas que retira o foco do problema significativamente maior. As empresas de tecnologia, por meio de seus aplicativos, programas de buscas na Internet via algoritmos, exploram a emoção das pessoas, impondo-lhes modelos de democracia e de negócios, além de outra visão de mundo.

Por fim, e concluindo, não existe conflito entre a LAI e a LGPD, bastando que o agente de tratamento utilize os seguintes filtros para manusear a informação: se houver interesse público, a informação deve ser publicada, do contrário, não; havendo interesse público, a informação possui dado pessoal sensível? Se a resposta for positiva, o tratamento reclama o assentimento ou, no extremo, previsão expressa da lei que afasta o consentimento do titular dos dados pessoais.

\section{REFERÊNCIAS}

ARRUDA, Pedro Fassoni. CAPITALISMO DEPENDENTE E RELAÇÕES DE PODER NO BRASIL: 1889-1930. São Paulo: Expressão Popular, 2012. 384 p.

ÁVILA, Vicente machado. NEOSOCIALISMO \& COOPERATIVISMO: DÉCADA DE 1990 - UMA PROPOSTA PARA DEBATE. Curitiba: Coração Brasil Editora, $2017.112 \mathrm{p}$.

BRASIL. Lei ordinária $n^{\circ} 12.527$, de 18 de novembro de 2011. Regula o acesso a informações previsto no inciso XXXIII do art. $5^{\circ}$, no inciso II do $\S 3^{\circ}$ do art. 37 e no $\S 2^{\circ}$ do art. 216 da Constituição Federal; altera a Lei $n^{\circ}$ 8.112, de 11 de dezembro de 1990; revoga a Lei $n^{\circ}$ 11.111, de 5 de maio de 2005, e dispositivos da Lei $n^{\circ} 8.159$, de 8 de janeiro de 1991; e dá outras providências

. Lei ordinária $n^{\circ} 12.965$, de 23 de abril de 2014. Estabelece princípios, garantias, direitos e deveres para uso da Internet no Brasil.

. Lei ordinária $n^{\circ} 13.709$, de 14 de agosto de 2018. Lei Geral de Proteção de Dados Pessoais (LGPD).

BRASIL. PGESP. CONVENÇÃO AMERICANA DE DIREITOS HUMANOS. Adotada e aberta à assinatura na Conferência Especializada Interamericana sobre Direitos Humanos, em San José de Costa Rica, em 22.11.1969 - ratificada pelo Brasil em 25.09.1992. Disponível em: http://www.pge.sp.gov.br/centrodeestudos/bibliotecavirtual/instrumentos/ sanjose.htm.

COGGIOLA, Osvaldo. DO MODERNO AO CONTEMPORÂNEO: UMA HISTÓRIA DO MUNDO NA ERA DO CAPITAL. São Paulo: Editora Livraria da Física, 2019. 881 p. 
CHAUÍ, Marilena. CONVITE À FILOSOFIA. São Paulo: Editora Ática, 2000. 567 p.

GIOVANNINI JUNIOR, Josmar Lenine. Fase 4: governança de dados pessoais. In LGPD: LEI GERAL DE PROTEÇÃODE DADOS PESSOAIS: MANUAL DE IMPLEMENTAÇÃO. MALDONADO, Viviane Nóbrega (coord.). São Paulo: Thomson Reuters Brasil, 2019. $368 \mathrm{p}$.

HARARI, Yiuval Noah. 21 LIÇÕES PARA O SÉCULO 21. São Paulo: Companhia das Letras, 2018. $302 \mathrm{p}$.

LEONARDI, Marcel. FUNDAMENTOS DE DIREITO DIGITAL. São Paulo: Thomson Reuters Brasil, 2019. 252 p.

LOUREIRO, Luiz Guilherme. MANUAL DE DIREITO NOTARIAL: da atividade e dos documentos notariais. Salvador: JusPODIVM, 2020. 992 p.

MARCACINI, Augusto Tavares Rosa. ASPECTOS FUNDAMENTAIS DO MARCO CIVIL DA INTERNET: Lei nº 12.965/2014. São Paulo: Edição do Autor, 2016. 134 p.

JUNIOR, Wallace Paiva Martins. TRANSPARÊNCIA ADMINISTRATIVA: PUBLICIDADE, MOTIVAÇÃO E PARTICIPAÇÃO POPULAR. São Paulo: Saraiva, 2010. 438 p.

\section{Vilson Pedro Nery}

Bacharel em Direito pela Universidade do Estado de Mato Grosso (UNEMAT). Mestre em Educação, pela Universidade Federal de Mato Grosso (UFMT). Mestrando em Direito pela Universidade de Ribeirão Preto (UNAERP). Especialista em Direito Público pela Universidade Cândido Mendes (UCAM). Especialista em Auditoria Governamental pela Faculdade de Ciências Sociais e Aplicadas de Diamantino (UNED). Especialista em Direito, Administração Pública e Controle Interno pela Fundação Getúlio Vargas (FGV). E-mail: vilsonery@gmail.com

Submetido em: $12-2-2021$

Aceito em: 22-7-2021 